\title{
An integrated Fuzzy DEMATEL and Fuzzy Cognitive Maps approach for the assessing of the Industry 4.0 Model
}

\section{DOI : 10.36909/jer.12303}

\author{
Enes Furkan Erkan*, Özer Uygun, Alper Kiraz, Onur Canpolat \\ Industrial Engineering Department, Sakarya University, Sakarya, Turkey. \\ *Email: eneserkan@sakarya.edu.tr
}

\begin{abstract}
Today, organizations are experiencing problems due to advancements in the environment, community, economy, and technology. In the future, physical and virtual systems, including the whole chain from product design to the distribution to customers and feedback will be required to overcome problems for organizations. Thus, companies need to comprehend and apply Industry 4.0. The most frequently encountered situation in the literature is the absence of research based on the practical experience of Industry 4.0 processes. In this study, the analysis of 9 concepts (Strategy, Leadership, Customers, Products, Operations, Culture, People, Governance, and Technology) is performed by utilizing the fuzzy DEMATEL and fuzzy AHP methods. As a result of both methods, Technology, Operations and Strategy concepts are obtained as the three most important concepts in the same rank in both methods. There is no significant change in the rank of the other concepts. Although close rankings are obtained from both methods, considering the interaction between the concepts and avoid shortcomings of consensus in the method, the ranking obtained by the fuzzy DEMATEL method is preferred to use as input in Fuzzy Cognitive Maps (FCMs). Then a relation map is formed based on their interaction and three alternative scenarios are created for FCMs from defuzzified total relation matrix data. As a result of scenarios, it is more useful for organizations to apply the Industry 4.0 processes to transfer their resources to their activities concerning the Strategies,
\end{abstract}


Technology, and Operations concepts. The aim is to predict the maturity levels of Industry 4.0 of organizations for the future by employing the FCMs methodology. Thanks to the introduced model based on the integration of fuzzy DEMATEL and FCMs, an insight is provided into which concepts should be prioritized about Industry 4.0.

Key words: digital transformation; fuzzy cognitive maps; fuzzy DEMATEL; Industry 4.0.

\section{INTRODUCTION}

At the end of the 18th century, the industrial revolution occurred because of replacing economic activities based on muscle and hand power by machine power and technological inventions. With the industrial revolutions, mass production has begun with considerable advancements in the production area in the world, production facilities have been created, and mechanization has been provided. As a result of these developments, Industry 4.0, which takes its origin from cyber-physical systems with the maximum level of technology usage and the combination of the internet and information technologies, has appeared (Diyadin and Koçak 2018).

Enterprises across the world encounter significant difficulties because of different advancements. In the future, physical and virtual structures, including the whole chain from the development of products and production order to the product distribution and recycling, starting from the idea phase, will be required for production organizations to overcome the abovementioned difficulties. The Industry 4.0 approach takes a key part in establishing the IT infrastructure of enterprises and in the transition to intelligent production/management (Park et al. 2016). It can transform product and service types and cause business models to be adapted. Companies, which understand their work completely, perform the analysis of their strong and weak aspects, and assess their progress in a systematic way, will be able to catch up with the mentioned alteration. In such a situation, it is of great importance for organizations to identify Industry 4.0 levels in the correct way and to take realistic and concrete measures in accordance with the present situation. Therefore, this study aims to determine the concepts that affect 
Industry 4.0, investigate the relationships and degrees between these concepts, and create a model that reveals the effects of the concepts on the Industry 4.0 maturity level.

When the literature is investigated, it is seen that many concepts affect Industry 4.0 (Table 1). Fuzzy DEMATEL is a very effective tool in determining the degree of inter-criteria connections in complex problems involving multiple criteria. This feature of fuzzy DEMATEL allows complex systems to be analyzed in detail and determined of essential criteria. It also provides a practical tool for decision-makers to compare the concepts of models with large dimensional matrices (Mazutto et al. 2018). In order to verify the ranking obtained from the criteria weights calculated by the fuzzy DEMATEL method, criteria weights are also calculated with the fuzzy AHP method. Based on the assumption that the concepts affecting the Industry 4.0 maturity level cannot be measured with mathematical models and that the concepts interact with each other, the fuzzy DEMATEL method is preferred to be used in the study.

In the fuzzy DEMATEL method, expert opinions are subjective, uncertain, and expressed with linguistic variables. In addition, interactions between concepts directly or indirectly affect decision-making performance. FCMs are a highly effective tool for the efficient analysis of complex problems involving these two features. FCMs are a successful tool for modeling the behavior of any system, representing the fundamental elements and cause-effect relationships between concepts (Azadeh et al. 2015). The developed model allows businesses to determine which concepts affect Industry 4.0 levels more and to determine Industry 4.0 levels independently of the sector by simulation. To the best of our knowledge, no research in which fuzzy DEMATEL and FCMs are applied to determine the Industry 4.0 maturity level addressed together is encountered. Most of the studies in the literature have been done using integrated MCDM techniques, and MCDM techniques do not allow simulation or scenario-based evaluation. The proposed model provides businesses with more helpful results about Industry 4.0 maturity levels. 
The rest of the paper is organized as follows: a literature review is provided in Section 2. Methods used in this paper are briefly described in Section 3. Information about the problem, flow chart, determination, and verification of concept weights are presented in Section 4. Section 5 provides an implementation of FCMs, and finally, the results are analyzed and discussed, and future studies are mentioned in Section 6.

\section{LITERATURE REVIEW}

Industry 4.0 has appeared on the basis of the concepts of cyber-physical systems, the internet of things, and big data. When the literature review is conducted, great attention is paid to the concepts in question in the research carried out on Industry 4.0. Despite insufficient research on Industry 4.0 in the literature, the number of studies in the mentioned area has recently increased at an accelerated rate.

Several reference models have been utilized with the aim of determining the Industry 4.0 maturity level. Among them, there are Impuls Industrie 4.0 Readiness (Lichtblau et al. 2015), Industry 4.0: Building the digital enterprise (PricewaterhouseCoopers 2016), and I4.0 Reifegradmodell (Jodlbauer and Schagerl 2016).

Cimini et al. assessed the reference models in the transition to intelligent production, and the models were gathered under three groups. In the first-group models, the emphasis is placed on cyber-physical systems in intelligent production. In the model in question, it is suggested to ensure the information flow from the operational level to ERP via control systems, including monitors and control systems. The second group of models provides more details on the information systems that are required for integration within and outside smart factories. First, the analysis of the standards for data exchange in accordance with the model in question should be conducted. In the final model, the reference architecture model is reviewed. The abovementioned model comprises a 3-dimensional structure. The first axis contains the product life cycle, while the second axis contains the functional hierarchy of the system, including workstations and control devices. There are six layers, including communication, business, 
information, and functions, on the final axis (Cimini et al. 2017).

Lichtblau et al. performed an evaluation of businesses at six dimensions in the Industrie 4.0 Readiness model (Lichtblau et al. 2015). PwC Company introduced as a result of their study, made an explanation of a digital roadmap in the Industry 4.0 transition processes in PwC's 2016 Global Industry 4.0 Survey report (PricewaterhouseCoopers 2016). In accordance with Schumacher et al., the maturity of an industrial organization and the internal and external conditions should be at a level to support the Industry 4.0 basic concepts. To determine the mentioned maturity level, the model comprises nine dimensions, including strategy, leadership, customers, products, operations, culture, regulations, employees, and technology. Twenty-three of 123 companies took part in the model in question, and the measurement of Industry 4.0 maturity was performed in accordance with the model (Schumacher et al. 2016). Table 1 presents the literature review of the reference models utilized to determine the Industry 4.0 maturity level.

Table 1 Several studies conducted on Industry 4.0.

\begin{tabular}{|c|c|c|c|c|}
\hline \multirow{2}{*}{ Reference } & \multirow{2}{*}{ Content } & \multicolumn{3}{|c|}{ Method } \\
\hline & & MCDM & Fuzzy Logic & Questionnaire \\
\hline (Kumar and & MCDM based hybrid framework is proposed to overcome the & & & \\
\hline Shankar, 2021) & Industry 4.0 barriers. & $\bullet$ & & \\
\hline (Torbacki 2021) & $\begin{array}{l}\text { Cybersecurity structure of Industry } 4.0 \text { is investigated for sustainable } \\
\text { manufacturing and hybrid MCDM method is developed for } \\
\text { assessment this structure. }\end{array}$ & $\bullet$ & & \\
\hline (Chang et al. 2021) & $\begin{array}{l}\text { A hybrid MCDM approach is developed to perform an assessment } \\
\text { that prioritizes the weights of Industry } 4.0 \text { for SMEs' factors. }\end{array}$ & $\bullet$ & & \\
\hline (Kaya et al. 2020) & A MCDM based road map was created for Industry 4.0 & $\bullet$ & • & \\
\hline $\begin{array}{l}\text { (Yıldızbaşı and } \\
\text { Ünlü, 2020) }\end{array}$ & $\begin{array}{l}\text { Fuzzy AHP and Fuzzy TOPSIS techniques were used for making } \\
\text { comparison between enterprises using Industry } 4.0 \text { technologies. }\end{array}$ & & $\bullet$ & \\
\hline $\begin{array}{c}\text { (Sriram and } \\
\text { Vinodh, 2020) }\end{array}$ & $\begin{array}{l}\text { Readiness factors are analysed for Industry } 4.0 \text { deployment in SMEs } \\
\text { using COPRAS method. }\end{array}$ & & & \\
\hline $\begin{array}{l}\text { (Mahdirajia et al. } \\
\text { 2020) }\end{array}$ & $\begin{array}{l}\text { A hybrid combination of BWM-TODIM model is suggested for } \\
\text { identifying priority strategies for implementing industry } 4.0 \text {. }\end{array}$ & $\bullet$ & $\bullet$ & \\
\hline (Özkurt 2020) & $\begin{array}{l}\text { identified, and the analysis of whether the companies are ready for } \\
\text { Industry } 4.0 \text { is performed in five manufacturing businesses. }\end{array}$ & & & $\bullet$ \\
\hline $\begin{array}{l}\text { (Erdogan et al. } \\
\text { 2018) }\end{array}$ & Best strategy for Industry 4.0 implementation is tried to find. & $\bullet$ & & \\
\hline $\begin{array}{l}\text { (Diyadin and } \\
\text { Koçak 2018) }\end{array}$ & $\begin{array}{l}\text { In the transition to Industry } 4.0,9 \text { critical success factors are assessed } \\
\text { by employing the DEMATEL method. }\end{array}$ & $\bullet$ & & \\
\hline $\begin{array}{l}\text { (Fengque et al. } \\
\text { 2017) }\end{array}$ & $\begin{array}{l}\text { The design and planning of the smart factory are reviewed in a } \\
\text { detailed manner based on Industry } 4.0 \text { and Made in China in } 2025 \text {. }\end{array}$ & & $\bullet$ & \\
\hline (Rojko 2017) & $\begin{array}{l}\text { The processing of Industry } 4.0 \text { concepts and reference architecture } \\
\text { model has been performed. }\end{array}$ & & & $\bullet$ \\
\hline (Lanza et al. 2016) & $\begin{array}{l}\text { Applications and strategies have been investigated in a detailed } \\
\text { manner to create the Industry } 4.0 \text { research, and an Industry } 4.0 \\
\text { roadmap has been formed. }\end{array}$ & & & • \\
\hline $\begin{array}{l}\text { (PricewaterhouseC } \\
\text { oopers 2016) }\end{array}$ & $\begin{array}{l}\text { A 6-dimensional model is utilized to achieve digital maturity at four } \\
\text { levels. }\end{array}$ & & & • \\
\hline $\begin{array}{l}\text { (Schumacher et al. } \\
\text { 2016) }\end{array}$ & $\begin{array}{l}\text { Industry } 4.0 \text { has proposed a model that consists of } 9 \text { criteria to } \\
\text { determine the maturity level. }\end{array}$ & & & • \\
\hline $\begin{array}{l}\text { (Lichtblau et al. } \\
\text { 2015) }\end{array}$ & $\begin{array}{l}\text { A 6-dimensional model has been suggested to measure the maturity } \\
\text { level of Industry } 4.0 \text {. }\end{array}$ & & & • \\
\hline
\end{tabular}




\section{METHODS}

In this study, firstly, the concept weights that will be utilized as the input of FCMs are found by employing the fuzzy DEMATEL method. Afterward, FCMs, which have been included in much recent research on the analysis of complicated systems, are utilized.

\section{Fuzzy DEMATEL Method}

The development of the fuzzy DEMATEL method is performed to obtain expert opinions and conduct the analysis of the cause-effect relationship of complex problems (Lin and $\mathrm{Wu} 2004$; Lin and $\mathrm{Wu}$ 2008). The above-mentioned method is chosen for establishing correlations among the introduced Industry 4.0 maturity model concepts.

In 1965, Zadeh introduced the commonly utilized fuzzy set theory (Zadeh 1965), referring to the problems of the real world, including ambiguity and fuzziness. The fuzzy DEMATEL method is wide-ranging and assists in obtaining a structural model between complex factors and their coherence.

In the fuzzy DEMATEL method, each expert creates a pairwise comparison matrix with linguistic expressions to measure the levels of relations between the criteria $\left\{C_{1}, C_{2}, \ldots, C_{\mathrm{n}}\right\}$. If there are $p$ decision making experts, $p$ decision matrix is obtained. The fuzzy direct relationship matrix is denoted as $\tilde{Z} . \tilde{Z}_{i j}$ triangular fuzzy number $\left(l_{i j}, m_{i j}, u_{i j}\right)$ is a linguistic term that indicates the level of influence of the factor $i$ to factor $j$.

$$
\begin{aligned}
& \tilde{x}=\frac{\tilde{z}_{i j}^{k}}{r^{(k)}}=\left(\frac{l_{i j}^{k}}{r^{(k)}}, \frac{m_{i j}{ }^{k}}{r^{(k)}}, \frac{u_{i j}^{k}}{r^{(k)}}\right) \\
& r^{k}=\max _{1<i<n}\left(\sum_{j=1}^{n} u_{i j}^{k}\right)
\end{aligned}
$$

The normalized relationship matrix is created using Equations 1 and 2 . In the equations, " $l$ " is the lower value of the triangular fuzzy numbers, " $m$ " is the medium number of the triangular fuzzy numbers, and " $u$ " is the upper value of the triangular fuzzy numbers. All upper values 
are summed as columns and a total value is found for each column with using Equation 2. The maximum of these values is the $r$ value. Then the whole matrix is divided by the $r$ and normalized direct relation matrix is obtained. The normalized direct relationship matrix is denoted by $\tilde{X}$.

$$
\tilde{X}=\left[\begin{array}{ccc}
\tilde{X}_{11} & \cdots & \tilde{X}_{1 n} \\
\vdots & \ddots & \vdots \\
\tilde{X}_{n 1} & \cdots & \tilde{X}_{n n}
\end{array}\right]
$$

After obtaining the normalized relationship matrix, the total relationship matrix will be created by using Equation 3.

$\tilde{T}=\sum_{i=1}^{\infty} \tilde{X}^{i}=\tilde{X}(I-\tilde{X})^{-1}$

After the $\tilde{T}$ matrix is obtained, $\widetilde{D}_{i}+\widetilde{R}_{i}$ and $\widetilde{D}_{i}-\widetilde{R}_{i}$ values are calculated, where $\widetilde{D}_{i}$ is the sum of the row elements and $\tilde{R}_{i}$ is the sum of the column elements (Tarim and Kandemir 2017). For any criterion $i, \widetilde{D}_{i}+\widetilde{R}_{i}$ is the total effect value of the criterion $i$. Likewise, for any criterion $i$, $\widetilde{D}_{i}-\widetilde{R}_{i}$ shows the effect value of the criterion $i$ on the whole system (Tarim and Kandemir 2017).

If the effect on the system is positive, the $i$ criterion is the "affecting" criterion, and if it is negative, the $i$ criterion is the "affected" criterion. Therefore, $\widetilde{D}_{i}-\widetilde{R}_{i}$ is called the degree of influence of the $i$ criterion on the system and $\widetilde{D}_{i}+\widetilde{R}_{i}$ is called the degree of role of the system (Çınar 2013).

Finally, the weight of criteria $(w)$ is calculated by Equation 4 and the normalized weights of criteria $(W)$ is calculated as Equation 5 (Zhang and Su 2019).

$$
\begin{aligned}
& w_{i}=\sqrt{\left(\widetilde{D}_{i}+\widetilde{R}_{i}\right)^{2}+\left(\widetilde{D}_{i}-\widetilde{R}_{i}\right)^{2}} \\
& W_{i}=\frac{w_{i}}{\sum_{i=1}^{n} w_{i}}
\end{aligned}
$$




\section{Fuzzy AHP Method}

Step 1: Degree analysis $\left(g_{i}\right)$ is performed by considering each criterion for each purpose. The results of $\mathrm{m}$ degree analysis $M_{g i}^{1}, M_{g i}^{2}, \ldots, M_{g i}^{m}$ of the objectives are expressed as fuzzy numbers. The fuzzy synthetic degree value for the criterion $\mathrm{i}$ is calculated using the following set of formulas (Equation 6).

$$
\begin{aligned}
& S_{i}=\sum_{j=1}^{m} M_{g_{i}}^{j} \otimes\left[\sum_{i=1}^{n} \sum_{j=1}^{m} M_{g_{i}}^{j}\right]^{-1} \quad i=\{1,2, \ldots, n\} \quad j=\{1,2, \ldots, m\} \\
& \sum_{j=1}^{m} M_{g_{i}}^{j}=\left(\sum_{j=1}^{m} l_{j}, \sum_{j=1}^{m} m_{j}, \sum_{j=1}^{m} u_{j}\right) \\
& {\left[\sum_{i=1}^{n} \sum_{j=1}^{m} M_{g_{i}}^{j}\right]^{-1}=\left(\frac{1}{\sum_{j=1}^{m} u_{j}}, \frac{1}{\sum_{j=1}^{m} m_{j}}, \frac{1}{\sum_{j=1}^{m} l_{j}}\right)}
\end{aligned}
$$

Step 2: $M_{1}=\left(l_{1}, m_{1}, u_{1}\right)$ and $M_{2}=\left(l_{2}, m_{2}, u_{2}\right)$, the degree of possibility is calculated with the help of the Equation 7.

$$
V\left(M_{2} \geq M_{1}\right)=\left\{\begin{array}{c}
1, m_{2} \geq m_{1} \\
0, l_{1} \geq u_{2} \\
\frac{l_{1}-u_{2}}{\left(m_{2}-u_{2}\right)-\left(m_{1}-l_{1}\right)}, \text { other }
\end{array}\right.
$$

Step 3: The minimum value obtained by comparing all $\mathrm{V}$ values for each criterion in the comparison matrix is taken as the weight value of that criterion, and thus the weight vector is obtained.

Step 4: The weight values of all criteria are added together.

Step 5: The weight value of each criterion is divided by the total weight value to obtain a normalized weight vector.

\section{Fuzzy Cognitive Maps}

FCMs were introduced by Kosko (1986) following the cognitive map method as a visually enriched decision support model to analyze complex systems (Axelrod 1976). FCMs examines the dynamic interactions and behavior of a system. FCMs are a graphical method that finds causal relationships between concepts of the system and is a simple way of describing the behavior of the system in a symbolic way, taking advantage of accumulated knowledge of the 
complex system (Groumpos 2010). FCMs are used for the analysis of institutionalization tendency because the problem is complex and requires expert knowledge. FCMs have been applied to various fields to solve related problems such as political and social sciences (May et al. 2017), medicine (Amirkhani et al. 2017), engineering (Shahinmoghaddam et al. 2018), environment and agriculture (Pacilly et al. 2016) in the literature.

As can be seen from Figure 1, FCMs represents the conceptual variables or elements forming the system, in which the direction between the nodes, the direction and weight of the arrows demonstrate the causal relations between the conceptual variables consisting of directed graphs (Yaman 2015).

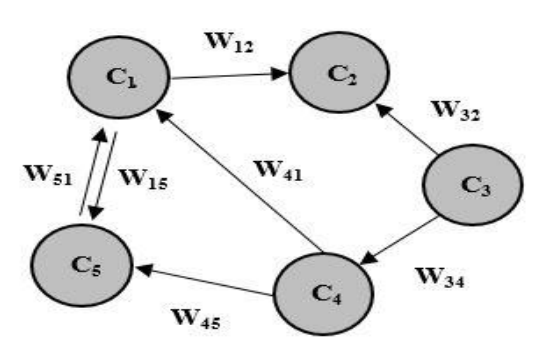

Figure 1 Simple FCMs.

The relations between the conceptual variables are described as fuzzy and vary between $[-1,1]$ and (Groumpos 2010). Thus, there are three various types of causal relations between the conceptual variables $C_{i}$ and $C_{j} . W_{i j}>0$ demonstrates a positive correlation between the conceptual variables $C_{i}$ and $C_{j}, W_{i j}<0$ demonstrates a negative correlation between the conceptual variables $C_{i}$ and $C_{j}$ and $W_{i j}=0$ demonstrates the absence of the correlation between the conceptual variables $C_{i}$ and $C_{j}$. The $W_{i j}$ the value indicates to what extent the conceptual variable $C_{i}$ will influence the conceptual variable $C_{j}$ (Papageorgiou 2010).

For every conceptual variable $C_{i}$, the conceptual variable value $\left(A_{i}\right)$ is computed in the way presented in Equations 8.

$$
A_{i}^{t}=f\left(\sum_{\substack{j=1 \\ j \neq i}}^{n} A_{j}^{t-1} W_{j i}+A_{i}^{t-1}\right)
$$


$A_{i}^{t}$ refers to the value of the conceptual variable $C_{i}$ at time t, $A_{i}^{t-1}$ refers to the value of $C_{j}$ conceptual variables $(t-1)$ at the time influencing the conceptual variable $C_{i}, W_{j i}$ refers to the impact value from the conceptual variable $C_{j}$ to the conceptual variable $C_{i}$, and $f$ denotes the threshold function.

The threshold functions that are frequently utilized in FCMs are presented in Equations 9 and 10 (Groumpos 2010).

$$
\begin{aligned}
& f(x)=\frac{1}{1+e^{-\lambda x}} \\
& f(x)=\tanh (x)
\end{aligned}
$$

\section{IMPLEMENTATION}

In this study, the definition of a model is made by determining 9 concepts influencing the maturity level of Industry 4.0. The determination of the concepts is performed by referring to (Schumacher et al. 2016). The above-mentioned concepts are assessed by ten experts in the context of the Industry 4.0 tendency, and the fuzzy DEMATEL method is employed to determine the interaction map. Afterward, the weights of interaction between the concepts are presented as input to the FCMs algorithm. Different scenarios are implemented with FCMs, and the analysis of the complex system is performed. The model concepts are briefly described in Table 2.

\begin{tabular}{|c|c|c|}
\hline \multicolumn{2}{|r|}{ Concepts } & Explanations \\
\hline $\mathrm{C} 1$ & Strategy & $\begin{array}{l}\text { Roadmap of Industry } 4.0 \text {; investments to be made, technologies that should be added, the adaptation of } \\
\text { business models }\end{array}$ \\
\hline $\mathrm{C} 2$ & Leadership & $\begin{array}{l}\text { The presence of central coordination for Industry } 4.0 \text {; the willingness of leaders, adaptability, management } \\
\text { competencies and methods, communication }\end{array}$ \\
\hline C3 & Customers & The digital media competence of customers, the usage of customer data, the digitization of sales/services \\
\hline C4 & Products & $\begin{array}{l}\text { The equipment of physical products with information and communication technology, the integration of } \\
\text { products into other systems, the individualization of products }\end{array}$ \\
\hline C5 & Operations & $\begin{array}{l}\text { Decentralization of processes, modeling, and simulation, a collaboration between disciplines/departments, self- } \\
\text { controlling autonomous processes }\end{array}$ \\
\hline C6 & Culture & Sharing of information, open innovation, and collaboration throughout the company \\
\hline C7 & People & $\begin{array}{l}\text { The skills and competencies of employees, their competence in information and communication technologies, } \\
\text { the openness of employees to newly developed technologies, autonomous employees }\end{array}$ \\
\hline C8 & Governance & Business laws for Industry 4.0, compliance of technological standards, protecting intellectual property \\
\hline
\end{tabular}

Table 2 Concepts and their explanations (Schumacher et al. 2016) 


\begin{tabular}{lll}
\hline C9 & $\begin{array}{l}\text { Technology } \\
\text { C10 }\end{array}$ & $\begin{array}{l}\text { The presence of modern information technology, the usage of mobile devices, the usage of machine-to- } \\
\text { computer communication }\end{array}$ \\
Tendency & The output concept influenced by the concepts in the model
\end{tabular}

Flow chart of the study is given in Figure 2. When the flow is examined, it is seen that the total relationship matrix found by the fuzzy DEMATEL method is included in the algorithm as the interaction weight matrix for FCMs. This is because the direction and existence of an interaction between concepts in the FCMs method require a consensus of experts. It is very challenging in such studies, where many experts are needed. Thus, innovation has been presented to the literature with the integration of the two methods.

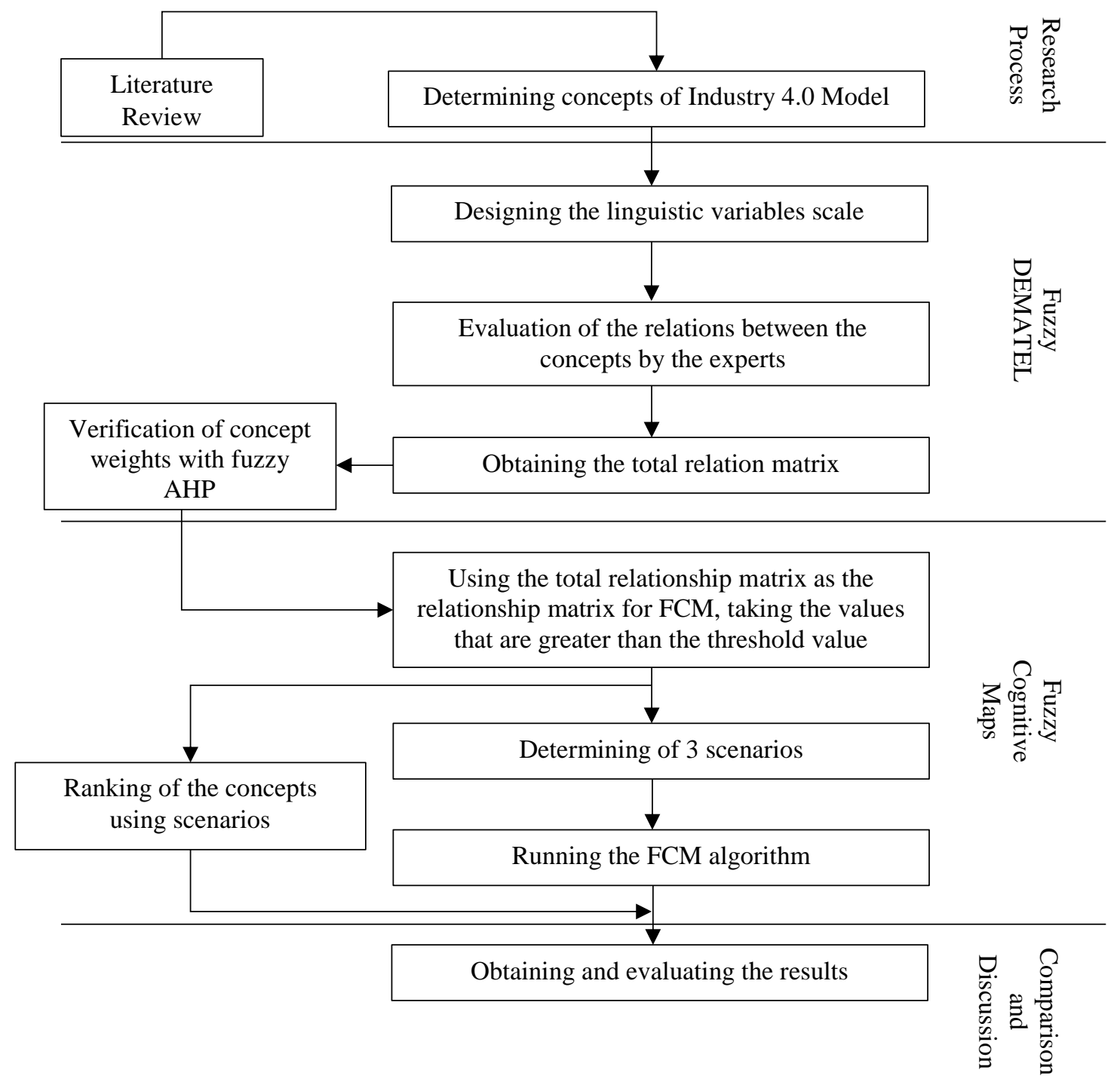

Figure 2 Application flow chart. 


\section{Determining Concept Weights with DEMATEL Method}

The concepts are assessed by ten experts by employing the fuzzy DEMATEL method. 5 of the experts are selected from the people working in companies providing consultancy in Industry 4.0 processes, and the other 5 are selected from academics working on the subject. In the assessment, ten experts are required to utilize the linguistic variables \{Very Low $(0,0,0.25)$, Low(0,0.25,0.5), Medium (0.25,0.5,0.75), High $(0.5,0.75,1)$, Very High $(0.75,1,1)\}$. Table 3 demonstrates the values assessed by expert 1 .

Table 3 The assessment of the concepts interaction by the $1^{\text {st }}$ expert .

\begin{tabular}{ccccccccccc}
\hline Concepts & C1 & C2 & C3 & C4 & C5 & C6 & C7 & C8 & C9 & C10 \\
\hline C1 & VL & H & M & VH & H & M & H & L & VH & VH \\
C2 & VH & VL & H & H & VH & VH & VH & L & H & H \\
C3 & M & L & VL & H & M & VL & H & VL & H & M \\
C4 & M & VL & L & VL & H & VL & M & VL & M & M \\
C5 & M & L & L & H & VL & L & M & L & M & VH \\
C6 & H & L & VL & VL & M & VL & VH & VL & M & H \\
C7 & H & M & VL & H & H & H & VL & VL & H & M \\
C8 & VH & H & L & VL & M & VL & H & VL & VH & H \\
C9 & VH & L & H & H & H & VL & M & VL & VL & VH \\
C10 & M & M & H & H & VH & M & H & VL & VH & VL \\
\hline
\end{tabular}

A single matrix is acquired due to taking the average of the values presented by ten experts, as demonstrated in Table 4. Afterward, a normalized, total-relation fuzzy matrix is acquired. Table 5 demonstrates the crisp values. Finally, the defuzzification of the total-relation fuzzy matrix is performed by converting fuzzy data into the crisp scores method in Table 6 (Irum et al. 2019). In the defuzzified total relationship matrix, the threshold value is found to be 0.16 by obtaining the opinion of experts. Values higher than 0.16 and determining the interactions and direction of the concepts are indicated in bold in Table 6. Figure 3 demonstrates the interactions between the concepts determined utilizing Table 6. The concept at the arrow's end shows the impacted concept.

The values that are indicated in bold which are higher than the threshold value in Table 6 determined by fuzzy DEMATEL are taken as the weight matrix of FCMs. After determining 
the weights of the relations between the concepts by the fuzzy DEMATEL method, the static analysis is applied for the scenario with regard to Industry 4.0.

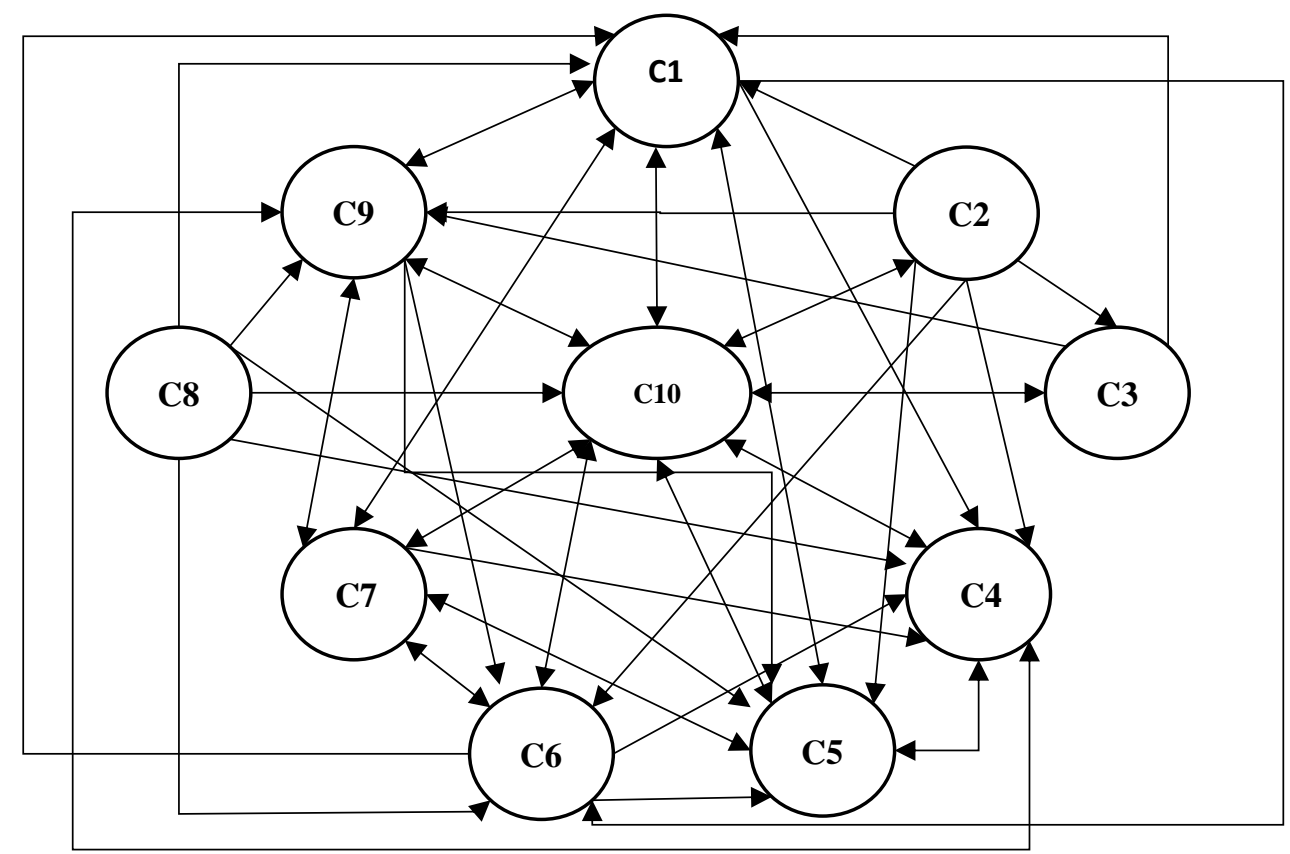

Figure 3 Interaction graph. 
Table 4 Direct-relation fuzzy matrix

\begin{tabular}{|c|c|c|c|c|c|c|c|c|c|c|c|c|c|c|c|c|c|c|c|c|c|c|c|c|c|c|c|c|c|c|}
\hline \multirow{2}{*}{ Concepts } & \multicolumn{3}{|c|}{$\mathrm{C} 1$} & \multicolumn{3}{|c|}{$\mathrm{C} 2$} & \multicolumn{3}{|c|}{ C3 } & \multicolumn{3}{|c|}{ C4 } & \multicolumn{3}{|c|}{ C5 } & \multicolumn{3}{|c|}{ C6 } & \multicolumn{3}{|c|}{ C7 } & \multicolumn{3}{|c|}{ C8 } & \multicolumn{3}{|c|}{ C9 } & \multicolumn{3}{|c|}{ C10 } \\
\hline & 1 & $\mathrm{~m}$ & $\mathrm{u}$ & 1 & $\mathrm{~m}$ & $\mathrm{u}$ & 1 & $\mathrm{~m}$ & $\mathrm{u}$ & 1 & $\mathrm{~m}$ & $\mathrm{u}$ & 1 & $\mathrm{~m}$ & $\mathrm{u}$ & 1 & $\mathrm{~m}$ & $\mathrm{u}$ & 1 & $\mathrm{~m}$ & $\mathrm{u}$ & 1 & $\mathrm{~m}$ & $\mathrm{u}$ & 1 & $\mathrm{~m}$ & $\mathrm{u}$ & 1 & $\mathrm{~m}$ & $\mathrm{u}$ \\
\hline C1 & 0 & 0 & 0 & 0.08 & 0.33 & 0.58 & 0.10 & 0.30 & 0.55 & 0.38 & 0.63 & 0.83 & 0.45 & 0.70 & 0.93 & 0.23 & 0.40 & 0.65 & 0.28 & 0.53 & 0.78 & 0.00 & 0.15 & 0.40 & 0.55 & 0.80 & 0.98 & 0.75 & 1 & 1 \\
\hline $\mathrm{C} 2$ & 0.60 & 0.85 & 0.95 & 0 & 0 & 0 & 0.15 & 0.33 & 0.58 & 0.38 & 0.60 & 0.83 & 0.73 & 0.98 & 1,00 & 0.53 & 0.78 & 0.98 & 0.43 & 0.68 & 0.85 & 0.05 & 0.28 & 0.53 & 0.50 & 0.75 & 1,00 & 0.5 & 0.75 & 1 \\
\hline $\mathrm{C} 3$ & 0.25 & 0.50 & 0.75 & 0.00 & 0.20 & 0.45 & 0 & 0 & 0 & 0.15 & 0.40 & 0.65 & 0.10 & 0.28 & 0.53 & 0.00 & 0.00 & 0.25 & 0.05 & 0.10 & 0.35 & 0.00 & 0.00 & 0.25 & 0.25 & 0.50 & 0.75 & 0.25 & 0.5 & 0.75 \\
\hline C4 & 0.15 & 0.38 & 0.63 & 0.00 & 0.00 & 0.25 & 0.15 & 0.40 & 0.65 & 0 & 0 & 0 & 0.28 & 0.53 & 0.78 & 0.00 & 0.03 & 0.28 & 0.25 & 0.48 & 0.73 & 0.03 & 0.08 & 0.33 & 0.23 & 0.43 & 0.65 & 0.25 & 0.5 & 0.75 \\
\hline C5 & 0.08 & 0.33 & 0.58 & 0.03 & 0.28 & 0.53 & 0.08 & 0.33 & 0.58 & 0.43 & 0.68 & 0.90 & 0 & 0 & 0 & 0.05 & 0.20 & 0.45 & 0.23 & 0.48 & 0.70 & 0.03 & 0.10 & 0.35 & 0.23 & 0.48 & 0.70 & 0.75 & 1 & 1 \\
\hline C6 & 0.18 & 0.43 & 0.68 & 0.20 & 0.45 & 0.70 & 0.05 & 0.15 & 0.40 & 0.15 & 0.38 & 0.63 & 0.43 & 0.68 & 0.85 & 0 & 0 & 0 & 0.30 & 0.55 & 0.78 & 0.10 & 0.20 & 0.45 & 0.03 & 0.15 & 0.40 & 0.5 & 0.75 & 1 \\
\hline C7 & 0.23 & 0.48 & 0.73 & 0.20 & 0.40 & 0.65 & 0.00 & 0.05 & 0.30 & 0.38 & 0.63 & 0.88 & 0.38 & 0.63 & 0.85 & 0.33 & 0.58 & 0.80 & 0 & 0 & 0 & 0.03 & 0.13 & 0.38 & 0.28 & 0.50 & 0.75 & 0.25 & 0.5 & 0.75 \\
\hline C8 & 0.25 & 0.50 & 0.73 & 0.18 & 0.38 & 0.63 & 0.00 & 0.05 & 0.30 & 0.20 & 0.40 & 0.65 & 0.20 & 0.45 & 0.70 & 0.03 & 0.13 & 0.38 & 0.13 & 0.30 & 0.55 & 0 & 0 & 0 & 0.33 & 0.55 & 0.78 & 0.5 & 0.75 & 1 \\
\hline C9 & 0.40 & 0.65 & 0.88 & 0.13 & 0.35 & 0.60 & 0.18 & 0.40 & 0.65 & 0.43 & 0.65 & 0.85 & 0.43 & 0.68 & 0.93 & 0.23 & 0.40 & 0.65 & 0.25 & 0.50 & 0.75 & 0.05 & 0.20 & 0.45 & 0 & 0 & 0 & 0.75 & 1 & 1 \\
\hline C10 & 0.25 & 0.5 & 0.75 & 0.25 & 0.5 & 0.75 & 0.5 & 0.75 & 1 & 0.5 & 0.75 & 1 & 0.75 & 1 & 1 & 0.25 & 0.5 & 0.75 & 0.5 & 0.75 & 1 & 0 & 0 & 0.25 & 0.75 & 1 & 1 & 0 & 0 & 0 \\
\hline
\end{tabular}

Table 5 Total relation fuzzy matrix

\begin{tabular}{|c|c|c|c|c|c|c|c|c|c|c|c|c|c|c|c|c|c|c|c|c|c|c|c|c|c|c|c|c|c|c|}
\hline \multirow{2}{*}{ Concepts } & \multicolumn{3}{|c|}{$\mathrm{C} 1$} & \multicolumn{3}{|c|}{$\mathrm{C} 2$} & \multicolumn{3}{|c|}{ C3 } & \multicolumn{3}{|c|}{$\mathrm{C} 4$} & \multicolumn{3}{|c|}{$\mathrm{C} 5$} & \multicolumn{3}{|c|}{ C6 } & \multicolumn{3}{|c|}{$\mathrm{C} 7$} & \multicolumn{3}{|c|}{$\mathrm{C} 8$} & \multicolumn{3}{|c|}{ C9 } & \multicolumn{3}{|c|}{$\mathrm{C} 10$} \\
\hline & 1 & $\mathrm{~m}$ & $\mathrm{u}$ & 1 & $\mathrm{~m}$ & $\mathrm{u}$ & 1 & $\mathrm{~m}$ & $\mathrm{u}$ & 1 & $\mathrm{~m}$ & $\mathrm{u}$ & 1 & $\mathrm{~m}$ & $\mathrm{u}$ & 1 & $\mathrm{~m}$ & $\mathrm{u}$ & 1 & $\mathrm{~m}$ & $\mathrm{u}$ & 1 & $\mathrm{~m}$ & $\mathrm{u}$ & 1 & $\mathrm{~m}$ & $\mathrm{u}$ & 1 & & $\mathrm{u}$ \\
\hline $\mathrm{C} 1$ & 0.01 & 0.08 & 0.40 & 0.02 & 0.09 & 0.38 & 0.02 & 0.09 & 0.37 & 0.08 & 0.18 & 0.54 & 0.09 & 0.20 & 0.57 & 0.04 & 0.11 & 0.40 & 0.06 & 0.15 & 0.49 & 0.00 & 0.05 & 0.28 & 0.10 & 0.19 & 0.54 & 0.13 & 0.26 & 0.66 \\
\hline $\mathrm{C} 2$ & 0.11 & 0.23 & 0.59 & 0.01 & 0.07 & 0.35 & 0.03 & 0.11 & 0.42 & 0.09 & 0.21 & 0.61 & 0.14 & 0.27 & 0.65 & 0.09 & 0.18 & 0.49 & 0.09 & 0.20 & 0.56 & 0.01 & 0.07 & 0.33 & 0.10 & 0.22 & 0.61 & 0.11 & 0.26 & 0.73 \\
\hline $\mathrm{C} 3$ & 0.04 & 0.12 & 0.39 & 0.00 & 0.05 & 0.28 & 0.00 & 0.03 & 0.21 & 0.03 & 0.11 & 0.40 & 0.02 & 0.09 & 0.40 & 0.00 & 0.03 & 0.26 & 0.01 & 0.06 & 0.33 & 0.00 & 0.01 & 0.20 & 0.04 & 0.12 & 0.40 & 0.05 & 0.13 & 0.48 \\
\hline $\mathrm{C} 4$ & 0.03 & 0.10 & 0.39 & 0.00 & 0.03 & 0.27 & 0.03 & 0.09 & 0.31 & 0.01 & 0.06 & 0.33 & 0.05 & 0.13 & 0.44 & 0.01 & 0.03 & 0.28 & 0.04 & 0.11 & 0.39 & 0.00 & 0.02 & 0.21 & 0.04 & 0.11 & 0.40 & 0.05 & 0.14 & 0.50 \\
\hline $\mathrm{C} 5$ & 0.02 & 0.11 & 0.42 & 0.01 & 0.07 & 0.33 & 0.01 & 0.08 & 0.33 & 0.07 & 0.16 & 0.48 & 0.01 & 0.07 & 0.38 & 0.01 & 0.07 & 0.33 & 0.04 & 0.12 & 0.42 & 0.00 & 0.03 & 0.24 & 0.04 & 0.13 & 0.44 & 0.12 & 0.23 & 0.59 \\
\hline C6 & 0.04 & 0.12 & 0.44 & 0.03 & 0.10 & 0.36 & 0.01 & 0.06 & 0.31 & 0.04 & 0.13 & 0.46 & 0.08 & 0.18 & 0.50 & 0.01 & 0.04 & 0.27 & 0.06 & 0.14 & 0.44 & 0.02 & 0.05 & 0.26 & 0.02 & 0.09 & 0.41 & 0.09 & 0.20 & 0.60 \\
\hline C7 & 0.05 & 0.14 & 0.47 & 0.03 & 0.10 & 0.37 & 0.01 & 0.05 & 0.32 & 0.07 & 0.17 & 0.52 & 0.08 & 0.18 & 0.54 & 0.06 & 0.13 & 0.40 & 0.01 & 0.07 & 0.36 & 0.01 & 0.04 & 0.27 & 0.05 & 0.14 & 0.49 & 0.06 & 0.17 & 0.59 \\
\hline C8 & 0.05 & 0.13 & 0.44 & 0.03 & 0.09 & 0.34 & 0.00 & 0.04 & 0.29 & 0.04 & 0.13 & 0.45 & 0.05 & 0.14 & 0.48 & 0.01 & 0.06 & 0.32 & 0.03 & 0.10 & 0.40 & 0.00 & 0.02 & 0.19 & 0.06 & 0.14 & 0.45 & 0.09 & 0.19 & 0.59 \\
\hline C9 & 0.07 & 0.17 & 0.52 & 0.02 & 0.10 & 0.39 & 0.03 & 0.10 & 0.38 & 0.08 & 0.18 & 0.54 & 0.08 & 0.19 & 0.57 & 0.04 & 0.11 & 0.40 & 0.05 & 0.15 & 0.49 & 0.01 & 0.05 & 0.29 & 0.02 & 0.08 & 0.41 & 0.13 & 0.25 & 0.66 \\
\hline C10 & 0.05 & 0.17 & 0.58 & 0.04 & 0.13 & 0.47 & 0.08 & 0.17 & 0.51 & 0.10 & 0.22 & 0.66 & 0.13 & 0.26 & 0.67 & 0.05 & 0.13 & 0.48 & 0.09 & 0.20 & 0.61 & 0.00 & 0.03 & 0.29 & 0.12 & 0.24 & 0.63 & 0.05 & 0.15 & 0.59 \\
\hline
\end{tabular}

Table 6 Defuzzified total relation matrix

\begin{tabular}{ccccccccccc}
\hline Concepts & C1 & C 2 & C 3 & C 4 & C 5 & C6 & C7 & C 8 & C 9 & C10 \\
\hline C 1 & 0.13 & 0.14 & 0.14 & $\mathbf{0 . 2 3}$ & $\mathbf{0 . 2 5}$ & $\mathbf{0 . 1 6}$ & $\mathbf{0 . 2 0}$ & 0.08 & $\mathbf{0 . 2 5}$ & $\mathbf{0 . 3 1}$ \\
C 2 & $\mathbf{0 . 2 8}$ & 0.11 & $\mathbf{0 . 1 6}$ & $\mathbf{0 . 2 7}$ & $\mathbf{0 . 3 2}$ & $\mathbf{0 . 2 3}$ & 0.15 & 0.12 & $\mathbf{0 . 2 7}$ & $\mathbf{0 . 3 2}$ \\
C 3 & $\mathbf{0 . 1 6}$ & 0.09 & 0.06 & 0.16 & 0.14 & 0.07 & 0.10 & 0.04 & $\mathbf{0 . 1 6}$ & $\mathbf{0 . 1 9}$ \\
C 4 & 0.15 & 0.07 & 0.12 & 0.10 & $\mathbf{0 . 1 8}$ & 0.07 & 0.16 & 0.05 & $\mathbf{0 . 1 6}$ & $\mathbf{0 . 2 0}$ \\
C5 & $\mathbf{0 . 1 6}$ & 0.12 & 0.12 & $\mathbf{0 . 2 1}$ & 0.13 & 0.11 & $\mathbf{0 . 1 7}$ & 0.06 & $\mathbf{0 . 1 8}$ & $\mathbf{0 . 2 8}$ \\
C6 & $\mathbf{0 . 1 8}$ & 0.15 & 0.10 & $\mathbf{0 . 1 8}$ & $\mathbf{0 . 2 3}$ & 0.08 & $\mathbf{0 . 1 9}$ & 0.08 & 0.15 & $\mathbf{0 . 2 6}$ \\
C 7 & $\mathbf{0 . 1 9}$ & 0.15 & 0.10 & $\mathbf{0 . 2 3}$ & $\mathbf{0 . 2 3}$ & $\mathbf{0 . 1 8}$ & 0.12 & 0.08 & $\mathbf{0 . 2 0}$ & $\mathbf{0 . 2 4}$ \\
C8 & $\mathbf{0 . 1 8}$ & 0.13 & 0.09 & $\mathbf{0 . 1 8}$ & $\mathbf{0 . 1 9}$ & 0.10 & 0.15 & 0.04 & $\mathbf{0 . 1 9}$ & $\mathbf{0 . 2 6}$ \\
C 9 & $\mathbf{0 . 2 2}$ & 0.14 & 0.15 & $\mathbf{0 . 2 4}$ & $\mathbf{0 . 2 5}$ & $\mathbf{0 . 1 6}$ & $\mathbf{0 . 2 0}$ & 0.09 & 0.14 & $\mathbf{0 . 3 1}$ \\
C10 & $\mathbf{0 . 2 3}$ & $\mathbf{0 . 1 9}$ & $\mathbf{0 . 2 2}$ & $\mathbf{0 . 2 8}$ & $\mathbf{0 . 3 1}$ & $\mathbf{0 . 1 9}$ & $\mathbf{0 . 2 6}$ & 0.07 & $\mathbf{0 . 3 0}$ & 0.12 \\
\hline
\end{tabular}




\section{Verification of Concept Weights with Fuzzy AHP method}

To verify the concept weights determined by the fuzzy DEMATEL method, the experts who created the relationship matrices in the fuzzy DEMATEL method created the comparison matrices of the concepts in accordance with the fuzzy AHP method. The fuzzy comparison matrix formed as a result of the opinions of 10 experts is shown in Table 7.

Table 7 Fuzzy AHP comparison matrix

\begin{tabular}{|c|c|c|c|c|c|c|c|c|c|c|c|c|c|c|c|c|c|c|c|c|c|c|c|c|c|c|c|c|c|c|c|c|c|}
\hline \multirow{2}{*}{$\mathrm{C}$} & \multicolumn{3}{|c|}{ C1 } & \multicolumn{3}{|c|}{$\mathrm{C} 2$} & \multicolumn{3}{|c|}{ C3 } & \multicolumn{4}{|c|}{$\mathrm{C} 4$} & \multicolumn{3}{|c|}{ C5 } & \multicolumn{4}{|c|}{ C6 } & \multicolumn{3}{|c|}{ C7 } & \multicolumn{3}{|c|}{ C8 } & \multicolumn{4}{|c|}{ C9 } & \multicolumn{3}{|c|}{ C10 } \\
\hline & 1 & $\mathrm{~m}$ & $\mathrm{u}$ & 1 & $\mathrm{~m}$ & $\mathrm{u}$ & 1 & $\mathrm{~m}$ & $\mathrm{u}$ & 1 & $\mathrm{n}$ & $n$ & $\mathrm{u}$ & 1 & $\mathrm{~m}$ & $\mathrm{u}$ & 1 & $\mathrm{~m}$ & $\underline{\mathrm{u}}$ & & & $\mathrm{m}$ & $\mathrm{u}$ & 1 & $\mathrm{~m}$ & $\mathrm{u}$ & 1 & $\mathrm{~m}$ & $\mathrm{n}$ & & & & \\
\hline $\mathrm{C} 1$ & 1.0 & 1.0 & 1.0 & 1.0 & 2.0 & 3.0 & 1.0 & 1.0 & 2.0 & 1.0 & 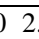 & 0 & & 0.3 & 0.3 & 0.5 & 2.0 & 3 & 4 & & 1.0 & 2.0 & 3.0 & 1.0 & 2.0 & & 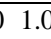 & 0 & & & 1.0 & & \\
\hline & & & & & 1.0 & & & & & & & & & & & & & & & & & 5 & & & & & & $\begin{array}{lll}30 & 0\end{array}$ & & & & 1.0 & \\
\hline & & & & & & & & & & & & & & & & & & & & & & & & & 1 & & & & & & & & \\
\hline & & & & & & & & & & & & & & & & & & & & & & & & & & & & & & & & 3.0 & \\
\hline$C$ & & & & & 6.0 & & & 2. & & & & & & & & & & & & & & & & & & & & $\begin{array}{ll}03 . \\
0\end{array}$ & & & 6 & 6.0 & \\
\hline & & & & 2 & 3. & & & I. & & & & & & & & & & & & & & 1.0 & & & & & & 0. & & & & 3.0 & \\
\hline & & & & & & & & & & & & & & & & & & & & & & & & & & & & & & & & & \\
\hline & & & & & & & & & & & & & & & & & & & & & & & & & & & & $\begin{array}{lll}3 & 0 .\end{array}$ & & & & & \\
\hline & & & & & & & & & & & & & & & 0 & & & & & & & 2.0 & & & & & 1.0 & 0 & & & 2.0 & 3.0 & \\
\hline & 1.0 & 1.0 & 1.0 & 1.0 & 2.0 & 3.0 & 1.0 & 1.0 & 2.0 & ) & & & 3.0 & 0.3 & 0.3 & 0.5 & 2.0 & ) & 4. & & 1.0 & 2.0 & 3.0 & 1.0 & 2.0 & 3.0 & 1. & $\begin{array}{ll}0 & 1 .\end{array}$ & & 1.0 & 1.02 & 2.03 & \\
\hline
\end{tabular}

After the defuzzification of the total-relation fuzzy matrix, the weights of the concepts $\left(W_{i}\right)$ determined by the fuzzy DEMATEL method and calculated in Equation 5 are shown in Table 8. Besides, the concepts weights calculated with the fuzzy AHP are also shown in Table 8.

Table 8 Concept weights of fuzzy DEMATEL

\begin{tabular}{ccccc}
\hline \multirow{2}{*}{ Concepts } & \multicolumn{2}{c}{ Fuzzy DEMATEL } & \multicolumn{2}{c}{ Fuzzy AHP } \\
& Weights & Rank & Weights & Rank \\
\hline C1 & $\mathbf{0 . 1 2 7 0}$ & $\mathbf{3}$ & $\mathbf{0 . 1 4 4 6}$ & $\mathbf{3}$ \\
C2 & 0.1265 & 4 & 0.0116 & 9 \\
C3 & 0.0788 & 9 & 0.0690 & 8 \\
C4 & 0.1159 & 6 & 0.1348 & 4 \\
C5 & $\mathbf{0 . 1 2 7 5}$ & $\mathbf{2}$ & $\mathbf{0 . 1 6 8 3}$ & $\mathbf{2}$ \\
C6 & 0.0978 & 7 & 0.0981 & 6 \\
C7 & 0.1184 & 5 & 0.1091 & 5 \\
C8 & 0.0791 & 8 & 0.0932 & 7 \\
C9 & $\mathbf{0 . 1 2 9 1}$ & $\mathbf{1}$ & $\mathbf{0 . 1 7 1 3}$ & $\mathbf{1}$ \\
\hline
\end{tabular}

As a result of the fuzzy AHP method applied with the evaluations of the same ten experts, no significant difference is found in the importance rank of the concepts. Since the fuzzy DEMATEL method also considers the interaction between criteria, it is preferred to be used in scenarios created with FCMs. 


\section{SCENARIOS of FUZZY COGNITIVE MAPS}

To identify changes made by the concepts on the $\mathrm{C} 10$ output value and determine importance of the concepts in terms of Industry 4.0, firstly the best scenario is taken as the baseline. In the baseline scenario, the activated value of all concepts is set to 1 , and the steady state vector is found by applying Equations 8 and 9 respectively. In Table 9, steady vectors of the baseline scenario are given.

Table 9 Baseline Scenario.

\begin{tabular}{lcccccccccc}
\hline & $\mathrm{C} 1$ & $\mathrm{C} 2$ & $\mathrm{C} 3$ & $\mathrm{C} 4$ & $\mathrm{C} 5$ & $\mathrm{C} 6$ & $\mathrm{C} 7$ & $\mathrm{C} 8$ & $\mathrm{C} 9$ & $\mathrm{C} 10$ \\
\hline$A_{\text {initial }}^{\text {baseline }}$ & 1 & 1 & 1 & 1 & 1 & 1 & 1 & 1 & 1 & 1 \\
$A_{\text {steadine }}^{\text {basely }}$ & 0.9089 & 0.709 & 0.7727 & 0.9273 & 0.9424 & 0.8363 & 0.8763 & 1 & 0.9192 & 0.954 \\
\hline
\end{tabular}

Initial concept values are clamped that are unchanged throughout the iterations by taking the value of 0 for each scenario to analyze the differences from the steady value of C10 output concept. Table 10 illustrates the differences between $\mathrm{C} 1$ values (clamped value) and the baseline scenario. These differences show how much the other concepts are affected when the clamped concept is 0 .

\begin{tabular}{|c|c|c|c|c|c|c|c|c|c|c|}
\hline & $\mathrm{C} 1$ & $\mathrm{C} 2$ & $\mathrm{C} 3$ & $\mathrm{C} 4$ & $\mathrm{C} 5$ & C6 & $\mathrm{C} 7$ & $\mathrm{C} 8$ & $\mathrm{C} 9$ & C10 \\
\hline$A_{\text {steady }}^{\text {baseline }}$ & 0.9089 & 0.709 & 0.7727 & 0.9273 & 0.9424 & 0.8363 & 0.8763 & 1 & 0.9192 & 0.954 \\
\hline$A_{\text {steady }}^{C 1(\text { clamped value }=0)}$ & 0 & 0.7081 & 0.7432 & 0.9082 & 0.9257 & 0.8095 & 0.8492 & 1 & 0.8966 & 0.9369 \\
\hline Difference & -0.9089 & -0.0009 & -0.0295 & -0.0191 & -0.0167 & -0.0268 & -0.0271 & 0 & -0.0226 & -0.0171 \\
\hline
\end{tabular}

The same procedure is applied for all concepts and ranking of importance is determined according to differences in Table 11 . For example, the $\mathrm{C} 1$ concept, which makes the most difference in the scenario, points to the most important concept in the proposed Industry 4.0 maturity model.

Table 11 Ranking of Concepts

\begin{tabular}{cccccccccc}
\hline Clamped Value $=0$ & C1 & C9 & C5 & C8 & C2 & C7 & C6 & C4 & C3 \\
\cline { 2 - 9 } Difference Output (C10) & -0.0171 & -0.0169 & -0.0151 & -0.0147 & -0.0136 & -0.0123 & -0.0122 & -0.0101 & -0.0076 \\
\hline
\end{tabular}

After the importance levels of the concepts are found with the help of scenarios, three case studies illustrate how organizations that are well, medium, and bad-managed in terms of 
Industry 4.0 are determined are created hypothetically. Results are obtained using the FCMs algorithm. In all three scenarios, the output value is set as 0.5 in the initial scenario.

During the determination of the first scenario, an organization that is managed well is taken into account. It is considered that expert opinions are obtained to determine initial state vector $\left(\mathrm{A}_{\mathrm{i}}\right.$ in Eq. 8) demonstrating organization's current status. As a threshold value function, sigmoid is selected since the values must be positive because of the characteristics of Industry 4.0 analysis. Table 12 presents the steady-state values occurring following the application of the Eq. 8 . Moreover, changes in every iteration are demonstrated in the graph in Figure 4.

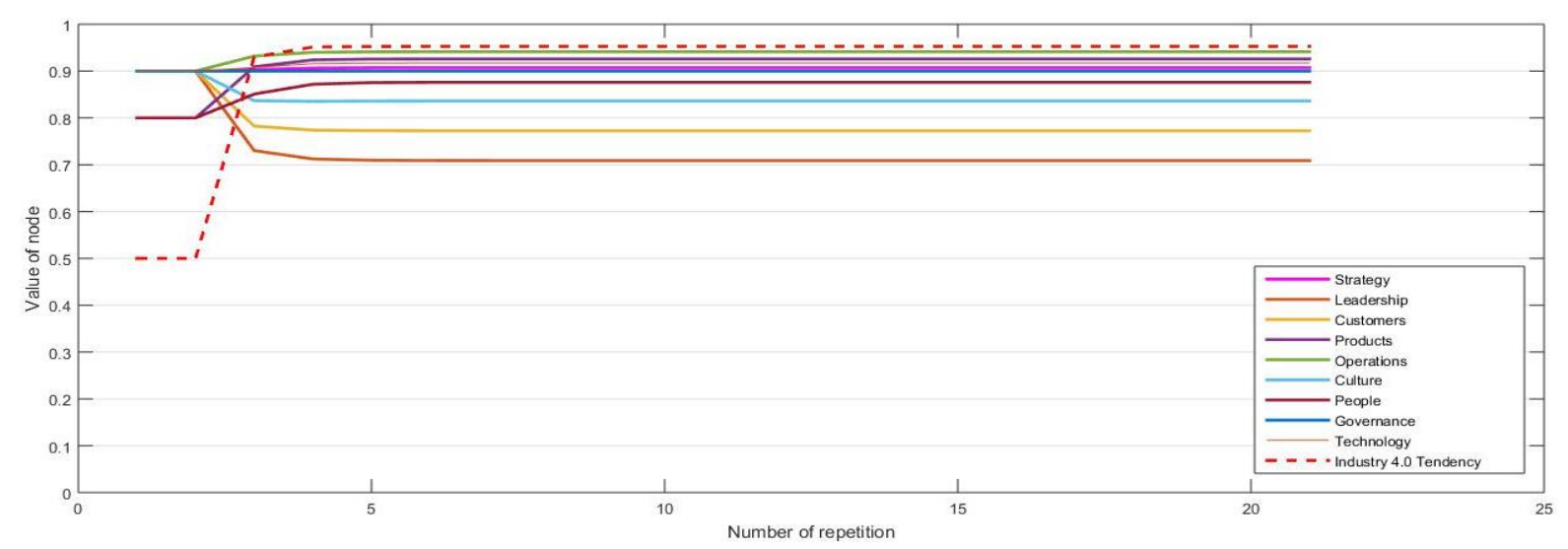

Figure 4 The first scenario's graph.

Table 12 FCMs implementations values of the first scenario

\begin{tabular}{ccccccccccc}
\hline & C1 & C2 & C3 & C4 & C5 & C6 & C7 & C8 & C9 & C10 \\
\hline$A_{\text {initial }}^{\text {S1 }}$ & 0.9 & 0.9 & 0.9 & 0.8 & 0.9 & 0.9 & 0.8 & 0.9 & 0.9 & 0.5 \\
$A_{\text {steady }}^{\text {S1 }}$ & 0.9072 & 0.7089 & 0.7725 & 0.9258 & 0.9412 & 0.8361 & 0.8761 & 0.9 & 0.9175 & 0.9527 \\
Difference & 0.0072 & -0.1911 & -0.1275 & 0.1258 & 0.0412 & -0.0639 & 0.0761 & 0 & 0.0175 & 0.4527 \\
\hline
\end{tabular}

As is observed from the graph, the Industry 4.0 trend has achieved a considerably good level of 95 by increasing 45.27 percent following the $7^{\text {th }}$ iteration because the organization's management is already performed well concerning Industry 4.0 processes. Furthermore, the support of the government in the country is good. The absence of the difference in the Governance (C8) concept is that it has not been affected from outside and has only influenced other concepts. A decrease has occurred only in the concept of customers (C3) due to impacted levels in the matrix and the VL impact. 
In the second scenario, a medium level company is considered. The initial values for the concepts are taken at a medium level and given into the FCMs algorithm. Table 13 shows the steady values after 7 iteration steps and the differences from the initial vector. Figure 5 presents the change of values graphically.

Table 13 FCMs implementations values of the second scenario.

\begin{tabular}{ccccccccccc}
\hline & $\mathrm{C} 1$ & $\mathrm{C} 2$ & $\mathrm{C} 3$ & $\mathrm{C} 4$ & $\mathrm{C} 5$ & $\mathrm{C} 6$ & $\mathrm{C} 7$ & $\mathrm{C} 8$ & $\mathrm{C} 9$ & $\mathrm{C} 10$ \\
\hline$A_{\text {initial }}^{\text {S2 }}$ & 0.5 & 0.4 & 0.5 & 0.5 & 0.4 & 0.6 & 0.6 & 0.5 & 0.5 & 0.5 \\
$A_{\text {steady }}^{\text {2 }}$ & 0.8999 & 0.7086 & 0.7720 & 0.9198 & 0.9361 & 0.8356 & 0.8753 & 0.5 & 0.9105 & 0.9471 \\
Difference & 0.3999 & 0.3086 & 0.272 & 0.4198 & 0.5361 & 0.2356 & 0.2753 & 0 & 0.4105 & 0.4471 \\
\hline
\end{tabular}

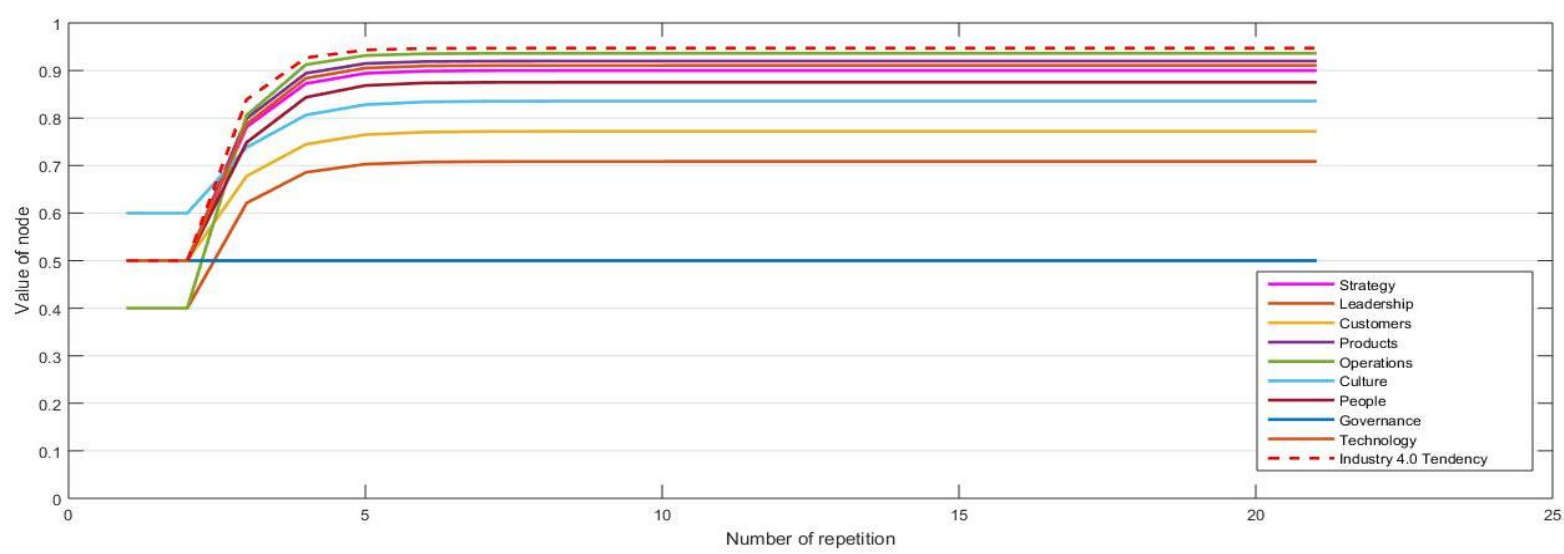

Figure 5 The second scenario's graph.

As shown in Figure 5, in this scenario with medium concept values, Industry 4.0 output value has reached a steady state with an increase of 44 percent. Customers and technology concepts are slightly less affected than others. The reason is that they are the least affected concepts in the model.

In the third scenario, the activating values of the concepts are taken lower than the other scenarios. The steady state vector and the resulting differences are given in Table 14. Figure 6 shows the changes in the graphical representation as a result of the iterations.

Table 14 FCMs implementations values of the third scenario.

\begin{tabular}{ccccccccccc}
\hline & $\mathrm{C} 1$ & $\mathrm{C} 2$ & $\mathrm{C} 3$ & $\mathrm{C} 4$ & $\mathrm{C} 5$ & $\mathrm{C} 6$ & $\mathrm{C} 7$ & $\mathrm{C} 8$ & $\mathrm{C} 9$ & $\mathrm{C} 10$ \\
\hline$A_{\text {initial }}^{\text {S3 }}$ & 0.1 & 0.1 & 0.1 & 0.1 & 0.2 & 0.1 & 0.2 & 0.1 & 0.1 & 0.5 \\
$A_{\text {steady }}^{\text {S }}$ & 0.8921 & 0.7083 & 0.7715 & 0.9133 & 0.9305 & 0.8350 & 0.8745 & 0.1000 & 0.9029 & 0.9409 \\
Difference & 0.7921 & 0.6083 & 0.6715 & 0.8133 & 0.7305 & 0.735 & 0.6745 & 0 & 0.8029 & 0.4409 \\
\hline
\end{tabular}


In this scenario, steady state vectors are reached after 9 iterations. A change of 44.09 percent occurred in the output concept. The governance concept has not changed in this scenario, as it has no effect from other concepts like other scenarios.

When the 3 scenarios are compared, it is seen that the output concept (C10) increases by 45.27 , 44.71, and 44.09 percent, respectively. These values are numerically close to each other. Still, the critical part of the evaluation is to divide the part between the best scenario and the worst scenario into the piece. Also, comments can be made not only about the output concept but also for other concepts in the model.

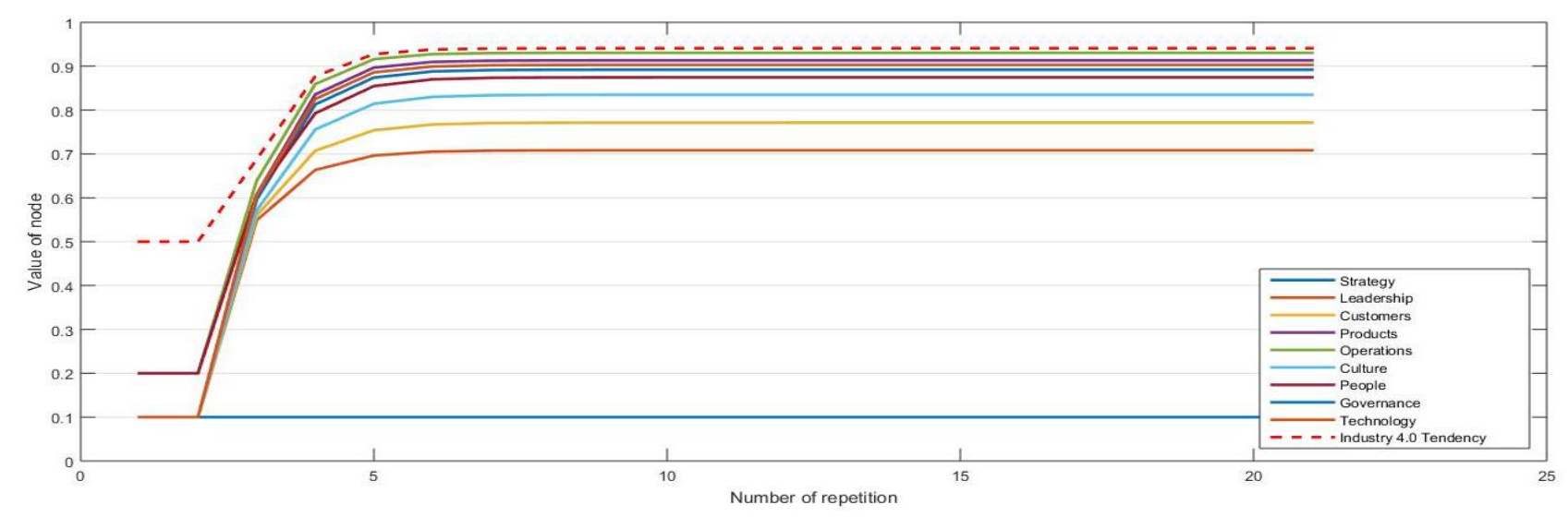

Figure 6 The third scenario's graph.

\section{CONCLUSIONS}

Industry 4.0 represents a process that enterprises should manage well. Under the digitalization and technology conditions, businesses function for sustainable lifecycles independently of particular employees or managers. If enterprises do not precisely know how to reach the required Industry 4.0 level, this will constitute a significant problem.

In this study, the concepts affecting Industry 4.0 are assessed by ten experts by employing the fuzzy DEMATEL and fuzzy AHP method, and the interaction map of the concepts is established. The results of the fuzzy DEMATEL method are used as inputs in the FCMs method since no significant change is observed in the concept rank, and the inter-concept relations are essential in the FCMs method. The fuzzy DEMATEL method eliminates the difficulty of 
consensus of experts to find interaction weights in the FCMs method. This study has proposed innovation in the literature concerning the integration of the two methods. Afterward, scenarios are formed in hypothetical terms, and the analysis of the future values of the concepts is conducted. According to the fuzzy DEMATEL results, causality relationships between all Industry 4.0 concepts are determined and Technology-C9 (0.1291), Operations-C5 (0.1275), and Strategy-C1 (0.1270) concepts stand out as the first three concepts that most affect enterprises' Industry 4.0 maturity level. No concept that is unrelated or does not affect Industry 4.0 has been encountered. For this reason, it may be helpful for companies to examine and evaluate these relationships for their strategic plans and roadmaps.

At the implementation of FCMs, firstly, to determine the concepts' influence degree on C10, the constant value of the relevant concept is calculated by setting it to 0 , respectively. As a result of this process, Strategy-C1 (-0.0171), Technology-C9 (-0.0169) and Operations-C5 (-0.0151) concepts are determined as the concepts that most affected the $\mathrm{C} 10$ output concept, in line with the results obtained in fuzzy DEMATEL. Then, three case studies are created that are well, medium and bad-managed.

While performing the scenarios, it is assumed that the initial Industry 4.0 maturity level is equal and 0.5 , ignoring how the company is managed. The well-managed scenario is achieved to 0.9527 in 7 repetitions, the medium-managed scenario is achieved to 0.9471 in 7 repetitions, and the bad-managed scenario is achieved to 0.9409 in 9 repetitions after FCMs implementation. The reason for this difference is that the input concepts have different degrees of influence. This fact shows the importance of the concepts included in the study, even in organizations with an initially equal level of Industry 4.0 maturity.

The main contributions of the proposed approach are summarized as follows: Developing an effective hierarchy to enable the assessment of Industry 4.0 maturity level, consideration of unclear, ambiguous statements and inputs in the proposed approach, considering the causal 
relationships between concepts and the degree of interaction between them, verification of concept rank determined by the proposed approach with fuzzy AHP, determining impact levels of the concepts on the Industry 4.0 and development of an Industry 4.0 maturity level measurement model applicable to all sectors.

Due to the introduced model, promising results that businesses can make use of are acquired. It is possible to determine the Industry 4.0 tendency for a scenario using the proposed model. The integration of other MCDM methods using FCMs to overcome the challenges of the consensus process of experts in mapping is regarded to be encouraging in future studies.

\section{REFERENCES}

Amirkhani, A., Papageorgiou E. I., Mohseni, A., \& Mosavi, M. R. 2017. A review of fuzzy cognitive maps in medicine: Taxonomy, methods, and applications. Computer Methods and Programs in Biomedicine. 142: 129-145.

Axelrod, R. 1976. Structure of decision: the cognitive maps of political elites. Princeton University Press. 422.

Azadeh, A., Zarrin, M., Abdollahi, M., Noury, S., \& Farahmand, S. 2015. Leanness assessment and optimization by fuzzy cognitive map and multivariate analysis. Expert Systems with Applications 42(15): 6050-6064.

Chang, S. C., Chang, H. H., Lu, M. T. 2021. Evaluating Industry 4.0 Technology Application in SMEs: Using a Hybrid MCDM Approach. Mathematics, 9(4), 414.

Cimini, C., Pinto, R., \& Cavalieri, S. 2017. The business transformation towards smart manufacturing: a literature overview about reference models and research agenda. IFACPapersOnLine. 50(1): 14952-14957.

Çınar, Y. 2013. A Structural Model of Career Preference Problem and Attitudes Towards Risk: A Hybrid Approach based on Stochastic DEMATEL Method. Sosyoekonomi, 19(19).

Diyadin, A., \& Koçak, A. 2018. Evaluation of Critical Success Factors in the Transitional 
Processes of Industry 4.0 using DEMATEL Method. Ege Academic Review. 18(1): 107120.

Erdogan, M., Ozkan, B., Karasan, A., Kaya, I. 2018. Selecting the best strategy for industry 4.0 applications with a case study. In Industrial engineering in the industry 4.0 era (pp. 109119). Springer, Cham.

Fengque, P., Yifei, T., Fei, H., \& Dongbo., L. 2017. Research on design of the smart factory for forging enterprise in the industry 4.0 environment. Mechanics. 23(1): 146-152.

Groumpos, P. P. 2010. Fuzzy cognitive maps: Basic theories and their application to complex systems, in Glykas M. (eds) Fuzzy Cognitive Maps. Studies in Fuzziness and Soft Computing. 1-22.

Irum, M., Shahzad, M., \& Muhammad, E. 2020. Fuzzy logic based prediction algorithm using nearest neighborhood clustering. Journal of Engineering Research. 8(3): 135-152.

Jodlbauer, H., \& Schagerl, M. 2016. Reifegradmodell Industrie 4.0 - Ein Vorgehensmodell zur Identifikation von Industrie 4.0 Potentialen. Informatik. 15: 1473-1487.

Kaya, I., Erdoğan, M., Karaşan, A., \& Özkan, B. 2020. Creating a road map for industry 4.0 by using an integrated fuzzy multicriteria decision-making methodology. Soft Computing, 24, 17931-17956.

Kiraz, A., Canpolat, O., Özkurt, C., Taşkın, H., Sarp, E. 2020. Examination of the criteria affecting Industry 4.0 with structural equation model and a pilot study. Journal of the Faculty of Engineering and Architecture of Gazi University 35(4): 2183-2196.

Kosko, B. 1986. Fuzzy cognitive maps. International Journal of Man-Machine Studies. 24(1): $65-75$.

Kumar, V., Vrat, P., Shankar, R. 2021. Prioritization of strategies to overcome the barriers in Industry 4.0: a hybrid MCDM approach. Opsearch, 1-40.

Lanza, G., Nyhuis, P., Ansari, S. M., Kuprat, T., \& Liebrecht, C. 2016. Empowerment and 
implementation strategies for Industry 4.0. Zeitschrift für wirtschaftlichen Fabrikbetrieb,

Lichtblau, K., et al. 2015. IMPULS - Industrie 4.0- Readiness. Impuls-Stift. VDMA.

Lin, C.-J., \& Wu, W.-W. 2004. A fuzzy extension of the DEMATEL method for group decision making. European Journal of Operational Research. 156: 445-455.

Lin, C.-J., \& Wu, W.-W. 2008. A causal analytical method for group decision-making under fuzzy environment. Expert Systems with Applications. 34(1): 205-2013.

Mahdiraji, H. A., Zavadskas, E. K., Skare, M., Kafshgar, F. Z. R., Arab, A. 2020. Evaluating strategies for implementing industry 4.0: a hybrid expert oriented approach of BWM and interval valued intuitionistic fuzzy TODIM. Economic research-Ekonomska istraživanja, 33(1), 1600-1620.

May, A. D., Lotfi, A., Langensiepen, C., Lee, K., \& Acampora, G. 2017. Human emotional understanding for empathetic companion robots. Advances in Computational Intelligence Systems. 513: 277-285.

Mazzuto, G., Stylios, C., \& Bevilacqua, M. 2018. Hybrid decision support system based on dematel and fuzzy cognitive maps. IFAC-PapersOnLine, 51(11), 1636-1642.

Pacilly, F. C. A., et al. 2016. Analysing potato late blight control as a social-ecological system using fuzzy cognitive mapping. Agronomy for Sustainable Development. 36(2): 35.

Papageorgiou, E. I., Markinos, A. T., \& Gemtos, T. A. 2010. Soft computing technique of fuzzy cognitive maps to connect yield defining parameters with yield in cotton crop production in central Greece as a basis for a decision support system for precision agriculture application. Fuzzy Cognitive Maps. 247: 325-362.

Park, E., Yoo, K., Kwon, S. J., Ohm, J., Chang, H. J. 2016. Effects of innovation cluster and type of core technology on firms' economic performance. Journal of Engineering Research 4(2): 117-131.

PricewaterhouseCoopers. 2016. Industry 4.0: Building the digital enterprise. 36. 
Rojko, A. 2017. Industry 4.0 concept: background and overview. International Journal of Interactive Mobile Technologies. 11(5): 77.

Schumacher, A., Erol, S., \& Sihn, W. 2016. A maturity model for assessing industry 4.0 readiness and maturity of manufacturing enterprises. Procedia CIRP. 52: 161-166.

Shahinmoghaddam, M., Nazari, A., \& Zandieh, M. 2018. CA-FCM: Towards a formal representation of expert's causal judgements over construction project changes. Advanced Engineering Informatics. 38: 620-638.

Sriram, R. M., \& Vinodh, S. 2020. Analysis of readiness factors for Industry 4.0 implementation in SMEs using COPRAS. International Journal of Quality \& Reliability Management, 38(5), 1178-1192.

Tarim, E. A., \& Kandemir, E. K. 2017. Visual program application for supplier selection using fuzzy DEMATEL and fuzzy AHP. 2017 International Conference on Computer Science and Engineering (UBMK) Antalya. 1055-1060.

Torbacki, W. 2021. A Hybrid MCDM Model Combining DANP and PROMETHEE II Methods for the Assessment of Cybersecurity in Industry 4.0. Sustainability, 13(16), 8833.

Yaman, D., Polat, S. (2015). Modeling Effect Based Operations Using Fuzzy Cognitive Maps and Simulation. İTÜ DERGİSİ/d, 6(2), 71-82.

Yıldıbaşı, A., \& Ünlü, V. 2020. Performance evaluation of SMEs towards Industry 4.0 using fuzzy group decision making methods. SN Applied Sciences, 2(3), 1-13.

Zadeh, L. 1965. Fuzzy sets. Information and Control. 8(3): 338-335.

Zhang, X., \& Su, J. 2019. A combined fuzzy DEMATEL and TOPSIS approach for estimating participants in knowledge-intensive crowdsourcing. Computers \& Industrial Engineering. 137: 106085. 